\title{
Prevalence and Risk Factors of Diabetes Mellitus in the Adult Population of Porto-Novo (Benin)
}

\author{
Daniel Amoussou-Guenou ${ }^{1}$, Armand Wanvoegbe ${ }^{2}$, Michel Hermans ${ }^{3}$, \\ Anthelme Agbodande', Marius Boko², Arnaulde Amoussou-Guenou Fandi', \\ Annelie Kerekou1 \\ ${ }^{1}$ National Hospital and University Centre 1 (CNHU), Cotonou, Benin \\ ${ }^{2}$ Departmental Hospital of Ouémé Plateau (CHUD-OP), Porto-Novo, Benin \\ ${ }^{3}$ Saint-Luc Clinic, Brussels, Belgium \\ ${ }^{4}$ Clinic of Akpakpa, Cotonou, Benin \\ Email: ㅁanielamousguen@yahoo.fr, wafinarm@yahoo.fr, michel.hermans@uclouvain.be, agbotem@yahoo.fr, \\ bokilson@yahoo.fr, aarnaulde@yahoo.fr, kerekouannelie@yahoo.fr
}

Received 4 May 2015; accepted 30 June 2015; published 3 July 2015

Copyright (C) 2015 by authors and Scientific Research Publishing Inc.

This work is licensed under the Creative Commons Attribution International License (CC BY). http://creativecommons.org/licenses/by/4.0/

(c) (i) Open Access

\begin{abstract}
Introduction: The aim of this study was to determine the prevalence and risk factors of diabetes mellitus in the adult population of Porto-Novo. Methods: A cross-sectional study with random sampling, stratified cluster, was used. Fasting blood glucose was measured in capillary blood (Accu-Chek Active). Diabetes mellitus was defined as fasting glucose $\geq 1.26 \mathrm{~g} / \mathrm{L}$, and fasting hyperglycemia in non-diabetic fasting glucose $\geq 1.10$ and $<1.26 \mathrm{~g} / \mathrm{L}$. Results: The survey involved 240 individuals. The sex ratio was 0.48 . The mean age was $46 \pm 13$ years (range 25 - 80 years). The prevalence of hyperglycemic patients was $7.9 \%$. The prevalence of diabetes was $6.7 \%$, including $3.3 \%$ of unknown diabetes, half of diabetics. The prevalence of fasting hyperglycemia without diabetes was $1.2 \%$. The risk factors for diabetes type 2 onset were a family history of diabetes $(p=0.017)$, older age $(p=0.003)$, hypertension $(p=0.005)$ and abdominal obesity (NCEP: $p=0.044 ;$ FID: $p=$ 0.001). Conclusion: These high figures confirm the increasing prevalence of diabetes mellitus in Benin, documented in many developing countries.
\end{abstract}

\section{Keywords}

Diabetes Prevalence, Risk Factors, Porto-Novo, Benin

\footnotetext{
${ }^{*}$ Corresponding author.

How to cite this paper: Amoussou-Guenou, D., Wanvoegbe, A., Hermans, M., Agbodande, A., Boko, M., Fandi, A.A.-G. and Kerekou, A. (2015) Prevalence and Risk Factors of Diabetes Mellitus in the Adult Population of Porto-Novo (Benin). Journal of Diabetes Mellitus, 5, 135-140. http://dx.doi.org/10.4236/jdm.2015.53016
} 


\section{Introduction}

Diabetes mellitus is one of the most common and worldwide non-communicable diseases [1] [2]. It is a major global public health issue because of its increasing frequency, morbidity, mortality, and its socio-economic cost [3].

The World Health Organization (WHO) estimated in 1995 that the prevalence of diabetes mellitus was about 135 million of adults worldwide [4]. This figure has increased significantly in recent decades, so that diabetes mellitus currently affects $381,800,000$ people worldwide (estimates of the International Diabetes Federation (IDF) 2013) [5]. IDF anticipates the increasing of this number to 591.9 million for 2035 , an increase of $55.0 \%$ [5]. This increase in number of diabetics is proportionately greater in developing countries, and will be more in Africa, where the number of diabetics is expected to increase, according to estimates of IDF, from 19.8 million in 2013 to 41,400,000 in 2035 [5]. Although the prevalence and progression of diabetes mellitus are well documented in industrialized countries, this is not the case in developing countries due to a lack of recent epidemiological, reliable and representative data [6], particularly in sub-Saharan Africa. [7]

In Benin, several prevalence surveys were conducted in the past. Thus, the frequency of diabetes mellitus was:

- $1.1 \%$ in 2001 [8], then measured at $2.6 \%$ in 2007 at the national level [9];

- $3.3 \%$ in Cotonou in 2002 [8], then measured at 4.6\% in 2007 [10];

- $0.9 \%$ in Oueme Department in 2007 [9].

Since 2007, to our knowledge, there have been no reports of diabetes mellitus prevalence in Porto-Novo, capital of the Republic of Benin. The present work was therefore designed to determine the prevalence and risk factors of diabetes mellitus type 2 in the urban adult population of Porto-Novo.

\section{Subjects and Methods}

The study was cross-sectional, descriptive and analytical, and was conducted according to the "STEP wise" approach recommended by WHO for the screening and monitoring of risk factors of non-communicable diseases [11]. It took place from June 1 to July 28, 2014. The target population consisted of adults of the five townships of Porto-Novo. Were included in the study, subjects aged 25 - 80 years, of both sexes, residing in Porto-Novo, and having given their consent. Fasting blood glucose was measured in capillary blood using a validated glucometer Accu-Chek Active. The diagnosis of diabetes mellitus was made on the basis of a recognized diabetes status and/or a fasting glucose $>$ or $=1.26 \mathrm{~g} / \mathrm{L}(7 \mathrm{mmol} / \mathrm{L})$.

Fasting hyperglycemia without diabetes (HJND) was defined with any person not known as diabetes based on fasting glucose and $>$ or $=1.10$ and $<1.26 \mathrm{~g} / \mathrm{L}$. The collected data were analyzed with the EPI INFO version 3.5.3 software. For comparisons between data, a value of $\mathrm{p}<0.05$ was considered statistically significant.

\section{Results}

\subsection{General Characteristics of the Population}

The minimum number of participants to include, calculated by the Schwartz formula, was 211 . This figure was increased by $10 \%$ to account for non-responders, resulting in a sampling size of 232 subjects, rounded 240 subjects included in the study.

The mean age of patients was $46.07 \pm 12.63$ years, with a range from 25 to 80 years. The age group $35-45$ was the most represented. Women were the majority (162 against 78 men), respectively $67.5 \%$ against $32.5 \%$ (sex ratio 0.48 ).

\subsection{Prevalence of Impaired Glucose Homeostasis}

The overall prevalence of hyperglycemia (diabetes mellitus and HJND) was $7.9 \%$; that of $1.2 \%$ HJND; and that diabetes mellitus was $6.7 \%$. Of the 16 patients with diabetes mellitus, 8 new cases were detected by the survey, representing $50 \%$ of all cases of diabetes mellitus, corresponding to a prevalence of unrecognized diabetes of $3.3 \%$ (Table 1).

\subsection{Diabetes Risk Factors (Table 2)}

\subsubsection{Sex}

The prevalence of diabetes mellitus was $6.4 \%$ for men against $6.8 \%$ in women $(p=0.91)$, suggesting that the sex 
Table 1. Subjects distribution according to the glycaemic profile.

\begin{tabular}{ccc}
\hline Fasting glucose & Number & Percentage \\
\hline Normal & 221 & 92.1 \\
Non-diabeticfasting hyperglycaemia & 3 & 1.2 \\
Diabetes mellitus & 16 & 6.7 \\
Total & 240 & 100 \\
\hline
\end{tabular}

Table 2. Summary of sought risk factors.

\begin{tabular}{|c|c|c|}
\hline & Diabetes prevalence (\%) & $\mathbf{p}$ \\
\hline \multicolumn{3}{|l|}{ Sex } \\
\hline $\mathrm{M}$ & 6.4 & \\
\hline $\mathrm{F}$ & 6.8 & 0.912 \\
\hline \multicolumn{3}{|l|}{ Age } \\
\hline$[25-35]$ & 0.0 & \\
\hline$[35-45]$ & 5.7 & \\
\hline$[45-55]$ & 3.7 & \\
\hline$[55-65]$ & 12.8 & \\
\hline$\geq 65$ & 21.7 & $\underline{0.003}$ \\
\hline \multicolumn{3}{|l|}{ HBP } \\
\hline yes & 11.3 & \\
\hline No & 2.4 & $\underline{0.005}$ \\
\hline \multicolumn{3}{|c|}{ Abdominal obesity } \\
\hline FID & No $\quad 0.0$ & $\underline{0.001}$ \\
\hline NCEP & No 3.8 & $\underline{0.044}$ \\
\hline \multicolumn{3}{|c|}{ Family history of diabetes } \\
\hline yes & \multicolumn{2}{|l|}{14.0} \\
\hline No & 4.7 & $\underline{0.017}$ \\
\hline
\end{tabular}

was not associated with an increased prevalence of diabetes (Table 2).

\subsubsection{Year 0ld}

The prevalence of diabetes increased with age of the subjects studied, with a peak of $21.7 \%$ among those aged ${ }^{3} 65$ years $(\mathrm{p}=0.003 \%)$.

\subsubsection{High Blood Pressure}

The prevalence of diabetes mellitus in hypertensive patients was $11.3 \%$ against $2.4 \%$ among non-hypertensive, with a statistically significant difference $(\mathrm{p}=0.005)$.

\subsubsection{Abdominal Obesity}

The prevalence of diabetes mellitus in subjects with abdominal obesity according to IDF criteria was $10.8 \%$ against $0.0 \%$ in patients with no abdominal obesity $(\mathrm{p}=0.001)$. According to the criteria of the National Cholesterol Education Program (NCEP), it was $10.3 \%$ in obese, against $3.8 \%$ in non-obese $(\mathrm{p}=0.044)$

\subsubsection{Family History of Diabetes}

The prevalence of diabetes mellitus in patients with a family history of diabetes mellitus (1 generational distance) was $14.0 \%$, against $4.7 \%$ in patients with no family history of diabetes mellitus $(p=0.017)$.

\section{Discussion}

\subsection{Population Characteristics}

The mean age of the study populations differed significantly between the prevalence studies available. Thus, the average age of patients in our study was 46.07 years, relatively close to those reported by Djrolo et al. (39.4 
years in Cotonou (Benin) in 2007) [10], for Balde et al. (49.4 years in 2007 to Labe (Guinea)) [12], for Mbaye et al. (43.4 years in 2011 in Saint-Louis (Senegal)) [13], and Oulad et al. (52 years in 2009 in Marrakech (Morocco)) [14].

Age over 40 years is an occurrence known risk factor for type 2 diabetes [15]. Ages of ${ }^{3} 65$ years and 55 - 64 were the most affected by diabetes. Our results are in line with those reported by Mbaye et al. St. Louis (Senegal) [13], where, in urban areas, ages 50 - 59 years and 60 - 69 years were the most represented.

In our survey, female was predominantly represented $67.5 \%$ of the sampled subjects and a sex ratio of 0.48 . This reflects the female population in Benin.

\subsection{Prevalence}

\subsubsection{Hyperglycemia in Non-Diabetic Fasting}

The prevalence of HJND was $1.2 \%$ in our study population, similar to that reported for Ouémé (1.2\%) in STEPS survey [9], but lower than that reported by Djrolo et al. (3.5\%) in Cotonou in 2007 [10] and Balde et al. (13.4\%) in Labe (Guinea) in 2007 [12]. It is also lower than that of Wang et al. (3.3\%) in China in 2009 [16] and Fagot et al. (5.6\%) in France in 2006 [17].

\subsubsection{Diabetes}

The prevalence of diabetes mellitus (known and unknown) was high in our study (6.7\%). It corresponds to the upper margin estimates for the urban black Africa, ranging from 2 to 6\% [18], signifying that the prevalence of diabetes mellitus is clearly increasing in Porto-Novo, like many other cities of the world. In Benin, at the end of STEPS survey in the general population, Djrolo et al. [9] in 2007 reported a prevalence of $0.9 \%$ in the department of Ouémé, and $2.6 \%$ nationally. This prevalence of $6.7 \%$ is close by against those reported by Balde et al. (6.1\%) in 2007 in Labe (Guinea) [12]; by Belhadj et al. (7.3\%) in 2010 in Algeria [19]; and that reported in Canada (7\%) in 2011 [20]. It is against superior to those reported by Lokrou et al. (1.33\%) in Abidjan (Ivory Coast) in 2000 [21]; by Djrolo et al. (4.6\%) in 2007 in Cotonou (Benin) [10]; Wang et al. (5.5\%) in 2009 in China [16]; and that reported in Seine-Saint Denis (France) to 5.8\% in 2006 [17]. This is certainly due to the aging of these studies at a time when the prevalence of the disease was lower than current rates.

The growing trend documented by this work is part of the global evolution of progression of diabetes mellitus [3] [22], usually attributed to a combination of changes in lifestyle (reduced physical activity) and changes in eating habits (safety and excess calories, fat intake increased, especially saturated fat, high glycemic index, rapidly absorbed sugars), favored by industrialization and urbanization.

However, the prevalence we found remains lower than that reported by Oulad et al. (10\%) to Marrakech (Morocco) [14] and Mbaye et al. (10.4\%) in 2011 in Saint-Louis (Senegal) [13]. These differences are probably related to ethnic regional differences; food; socio-cultural; and cardio-metabolic groups studied.

In our study, the prevalence of unrecognized diabetes was 3.3\%, about half of people with diabetes mellitus. This high prevalence of unrecognized diabetes is similar to that reported by Djrolo et al. (3.4\%) in 2007 in Cotonou [10] but exceeds that reported by Mbaye et al. (2.6\%) in 2011 in Saint-Louis (Senegal) [13]. This high rate justifies a proactive policy of screening for this population at risk of vascular complications in the long term, due to the lack of support for chronic hyperglycemia.

\subsection{The Risk Factors for Diabetes Mellitus}

An association between diabetes mellitus and age was highlighted in the statement $(p=0.003)$. This is consistent with the observation that the incidence of diabetes mellitus increases with age especially after 40 years. We do not, for contrary, observe statistically significant differences in the prevalence of diabetes mellitus gender $(\mathrm{p}=$ 0.91 ). Sex does not appear as a risk factor of diabetes mellitus in our study, and the relative prevalence of diabetes was almost equal between the sexes ( $6.4 \%$ for men against $6.8 \%$ for women). This finding is similar to that reported by Djrolo et al. (4.7\% versus 4.5\%) in Cotonou in 2007 [10], for Balde et al. (6.2\% versus 6.1\%) in Labe (Guinea) in 2007 [12] and by Mbaye et al. (10.2\% versus 10.5\%) in Saint-Louis (Senegal) in 2011 [13]. Prevalence in male was reported in France in 2010 (6.4\% against 4.5\%) [23] and Madagascar in 2005 [24]. On the other hand, Algeria [25] and Niger [26], the surveys were found higher in women.

In our study, the difference in the prevalence of diabetes mellitus in hypertensive and non-hypertensive patients was statistically significant $(\mathrm{p}=0.005)$. High blood pressure (hypertension) is a cardio-metabolic factor 
usually associated with the common form of type 2 diabetes, insulin resistance, central obesity and metabolic syndrome. This is consistent with the majority of the literature data. Indeed, Mbaye in Senegal [13], Dembele in Mali [27], Lokrou in Ivory Coast [21], Akintewe in Nigeria [28], Balde in Guinea [12] and Wang in China [16] reported an association between frequent diabetes mellitus and hypertension.

The prevalence of diabetes mellitus in subjects with abdominal obesity was 10.3\% (NCEP criteria) and 10.8\% (IDF criteria). These rates are lower than those reported by Mbaye et al. St. Louis (Senegal) $52.0 \%$ (NCEP) and $73.6 \%$ (IDF) [13]. The prevalence of diabetes mellitus was against by only $3.8 \%$ (NCEP) and zero (FID) in subjects with no excess weight. Whatever the criteria used, an association between diabetes mellitus and abdominal obesity was highlighted (NCEP: $\mathrm{p}=0.044$; FID: $\mathrm{p}=0.001$ ), confirming that abdominal obesity is a major risk factor for diabetes mellitus type 2. This finding is similar to that of Mbaye et al. in Senegal in 2011 [13].

Many opinions demonstrate a strong association between parental heredity and the onset of type 2 diabetes [13], due to a transmission traits predisposing to insulin resistance; obesity; and/or the accelerated loss of insulin secretory function $\beta$. Our results in this direction, showing a statistical association between family history of diabetes and the prevalence of diabetes mellitus $(p=0.017)$. And family history of diabetes mellitus was a risk factor of diabetes mellitus in Wang's report in China [16] and in Mbaye's in Senegal [13].

\section{Conclusion}

This study documented a high prevalence of diabetes mellitus $(6.7 \%)$ in an urban adult population of PortoNovo in Benin, confirming the alarming increase in prevalence of the disease; half of the cases were unknown. These data confirm the literature data showing that diabetes mellitus is growing rapidly in developing countries; the urban environment is a highly diabetogenic environment.

\section{References}

[1] Shaw, J.E., Sicree, R.A. and Zimmet, P.Z. (2010) Global Estimates of the Prevalence of Diabetes for 2010 and 2030. Diabetes Research and Clinical Practice, 87, 4-14. http://dx.doi.org/10.1016/j.diabres.2009.10.007

[2] Whiting, D.R., Guariguata, L., Weil, C. and Shaw, J. (2011) IDF Diabetes Atlas: Global Estimates of the Prevalence of Diabetes for 2011 and 2030. Diabetes Research and Clinical Practice, 94, 311-321. http://dx.doi.org/10.1016/j.diabres.2011.10.029

[3] Wild, S., Roglic, G., Green, A., Sicree, R. and King, H. (2004) Global Prevalence of Diabetes: Estimates for the Year 2000 and Projections for 2030. Diabetes Care, 27, 1047-1053. http://dx.doi.org/10.2337/diacare.27.5.1047

[4] Mbugua, P.K., Otieno, C.F., Kayima, J.K., Amayo, A.A. and McLigeyo, S.O. (2005) Diabetic Ketoacidosis: Clinical Presentation and Precipitating Factors at Kenyatta National Hospital, Nairobi. East African Medical Journal, 82, 191196.

[5] Guarignata, L., Whiting, D.R., Beagley, J., Linnenkamp, U., Hambleton, I., Cho, N.H., et al. (2013) Global Estimates of Diabetes Prevalence in Adults for 2013 and Projection for 2035 for the IDF Diabetes Atlas. Diabetes Research and Clinical Practice, 103, 137-149.

[6] Labie, D. (2007) Le diabète en Afrique sub-saharienne. Médecine Sciences (Paris), 23, 320-322. http://dx.doi.org/10.1051/medsci/2007233320

[7] Mbanya, J.C., Motala, A.A., Sobngwi, E., Assah, F.K. and Enoru, S.T. (2010) Diabetes in Sub-Saharan Africa. The Lancet, 375, 2254-2266. http://dx.doi.org/10.1016/S0140-6736(10)60550-8

[8] Djrolo, F., Amoussou-Guénou, K.D., Zannou, D.M., Houinato, D., Ahouandogbo, F. and Houngbe F. (2003) Prévalence du diabètesucré au Bénin. Louvain Médical, 122, S258-S262.

[9] Rapport final del'enquête STEPS au Bénin (2008) Direction Nationale de la Projection Sanitaire. Programme Nationale de Luttecontre les Maladies Non Transmissibles.

[10] Djrolo, F., Houinato, D., Gbary, A., Akoha, R., Djigbénoudé, O. and Sègnon, J. (2012) Prévalence du diabètesucrédansune population urbaine en milieu africain à Cotonou—Bénin. Médecine des maladies Métaboliques, 6, 167-169. http://dx.doi.org/10.1016/S1957-2557(12)70386-3

[11] Organisationmondiale de la santé (OMS), Le Manuel de surveillance STEPS de l'OMS (2005) L'approche STEP wise de l'OMS pour la surveillance des facteurs de risque des maladies chroniques-4. Manuel de Surveillance STEPS de l'OMS, Organisationmondiale de la santé, Genève.

[12] Baldé, N.M., Diallo, I., Baldé, M.D., Barry, I.S., Kaba, L., Diallo, M.M., et al. (2007) Diabetes and Impaired Fasting Glucose in Rural and Urban Populations in Futa Jallon (Guinea): Prevalence and Associated Risk Factors. Diabetes \& 
Metabolism, 33,114-120. http://dx.doi.org/10.1016/j.diabet.2006.10.001

[13] Mbaye, M., Niang, K., Sarr, A., Mbaye, A., Diedhiou, D., Ndao, M.-D., et al. (2011) Aspects épidémiologiques du diabète au Sénégal: Résultats d'une enquête sur les facteurs de risque cardiovasculaire dans la ville de Saint-Louis. Médecine des Maladies Métaboliques, 5, 659-664. http://dx.doi.org/10.1016/S1957-2557(11)70343-1

[14] OuladSayad, N., Ouhdouch, F. and Diouri, A. (2009) P108: Profil épidémiologique et clinique des diabétiques de Demnat (Région de Marrakech). Diabetes \& Metabolism, 35, 53-54.

[15] Simon, D. (2008) Définition, dépistageetépidémiologie du diabète de type 2. Médecine des maladies Métaboliques, 2 , S5-S9.

[16] Wang, H., Qiu, Q., Tan, L., Liu, T., Deng, X.Q., Chen, Y.M., et al. (2009) Prevalence and Determinants of Diabetes and Impaired Fasting Glucose among Urban Community-Dwelling Adults in Guangzhou, China. Diabetes \& Metabolism, 35, 378-384.

[17] Bonaldi, C., Vernay, M., Roudier, C., Salanave, B., Castetbon, K. and Fagot-Campagna, A. (2009) O68 Prévalence du diabète chez les adultes âgés de 18 à 74 ans résidant en France métropolitaine. Étude nationale nutrition santé, 20062007. Diabetes \& Metabolism, 35, A18. http://dx.doi.org/10.1016/S1262-3636(09)71760-4

[18] Sobngwi, E., Mauvais-Jarvis, F., Vexiau, P., Mbanya, J.C. and Gautier, J.F. (2001) Diabetes in Africans. Part 1: Epidemiology and Clinical Specificities. Diabetes \& Metabolism, 27, 628-634.

[19] Belhadj, M., Malek, R., Boudiba, A., Lezzar, E., Roula, D., Sekkal, F., et al. (2011) DiabCare Algérie. Médecine des Maladies Métaboliques, 5, 24-28. http://dx.doi.org/10.1016/S1957-2557(11)70068-2

[20] Agence de la santé publique du Canada, Le diabète au Canada (2011) Perspective de santé publiquesur les faitsetchiffres. Agence de la santé publique du Canada, Ottawa.

[21] Lokrou, A., Abodo, J., Yoboué, L. and Sanogo, A. (2008) Le diabète sucré à l'hôpital militaire d'Abidjan: Une série ambulatoire de 473 cas. Diabetes \& Metabolism, 2, 639-642.

[22] King, H. and Rewers, M., WHO Ad Hoc Diabetes Reporting Group (1993) Global Estimates for Prevalence of Diabetes Mellitus and Impaired Glucose Tolerance in Adults. Diabetes Care, 16, 157-177. http://dx.doi.org/10.2337/diacare.16.1.157

[23] Fagot-Campagna, A., Romon, I., Fosse, S. and Roudier, C., Institut de veille sanitaire (2010) Prévalence et incidence du diabète, et mortalité liée au diabète en France-Synthèse épidémiologique. Bulletin épidémiologique hebdomadaire, 42, 425-431.

[24] Direction de la promotion de la santé, service de luttecontre les maladies liées au mode de vie (2005) Enquêtesur les facteurs de risque des maladies non transmissibles à Madagascar selonl'approche STEPS de l'OMS. Madagascar.

[25] Ministère de la Santé, de la Population et de la Réformehospitalière (2005) Mesure des facteurs de risque des maladies non transmissiblesdans les deux Wilayaspilotes en Algérieselonl'approche STEPS de l'OMS. Algérie.

[26] Direction de la luttecontre les maladies etendémies (2007) Enquêtesur les facteurs de risque des maladies non transmissibles au Niger selonl'approche STEPS de l'OMS. République du Niger.

[27] Dembelé, M., Sidibé, A.T., Traoré, H.A., Tchombou, H.I.C., Zounet, B., Traore, A.K., et al. (2000) Association HTADiabètesucrédans le service de médecine interne de l'Hôpital Point G-Bamako. Médecine d'Afrique Noire, 47, 276280.

[28] Akintewe, T.A. and Adetuyibi, A. (1986) Obesity and Hypertension in Diabetics Nigerians. Tropical and Geographical Medicine, 38, 146-149. 